\title{
Indicators of Mineral Metabolism Depending on the Body Mass Index
}

\section{Olga Marshinskaia1, Tatiana Kazakova1, Svetlana Notova1, and Marat Gedulianov² \\ ${ }^{1}$ Federal Research Centre of Biological Systems and Agrotechnologies RAS, Orenburg, Russia \\ ${ }^{2}$ Federal State Institution Central Research Institute of Dental and Maxillofacial Surgery, Ministry of Health of the Russian Federation, 16, Timura Frunze str., Moscow, Russia}

ORCID:

Olga Marshinskaia: http://orcid.org/0000-0001-9031-3534

\section{Abstract}

In this study, the elemental status of the hair of adolescent girls in the Orenburg region $(n=120)$ with different levels of body mass index was studied and their average daily diet was evaluated. A nutrition assessment program was used to study the diet. Estimation of the element status was carried out through the study of the chemical composition of the hair by ICP-AES and ICP-MS. It was found that there was a general imbalance of elements in the diet of all of the studied groups, and students with obesity had lower consumption levels of all elements, except Mg and Se. Similarly, obese students had lower levels of all elements in their hair except Se, P, and Zn. Thus, changes in the level of body mass index, as well as geochemical features of the territory of the Orenburg region, affect the content of most macro- and microelements.

Keywords: metabolic syndrome, trace elements, body mass index

\section{Introduction}

There are various definitions of metabolic syndrome (MS) offered by numerous health organizations (for example, NCEP, IDF, AACE, and others), but in most cases the differences are insignificant. The world health organization (WHO) defines MS as a pathological condition characterized by abdominal obesity, insulin resistance, hypertension and hyperlipidemia. [1] People with MS have an increased risk of developing cardiovascular diseases and type 2 diabetes [2-5]

The global prevalence of MS can be estimated at about one-quarter of the world's population, which is more than a billion people [1]

Analysis of literature data shows that obesity is the basis of most cases of metabolic syndrome, being a marker of adipose tissue dysfunction [2, 6-7]. This statement also confirms the fact that the prevalence of metabolic syndrome often coincides with the 
prevalence of obesity and the incidence of type 2 diabetes [1] It is important to note that the growth rate of this problem continues to increase [8]. Research in recent years shows that more than 1.9 billion adults worldwide are already overweight and 650 million are obese. Approximately 2.8 million deaths are reported as a result of being overweight or obese [9]. One of the diagnostic indicators of obesity is the body mass index (BMI), which allows us to assess the degree of compliance of a person's weight and height, and thus indirectly judge whether the mass is insufficient, normal or excessive [10-11].

. A group of Israeli scientists has shown that a normal BMI makes it possible to exclude the presence of metabolic syndrome in men and women at any age [12]. Thus, current research shows that $\mathrm{BMI}$, along with other factors, is an easy-to-use indicator that is a predictor of metabolic syndrome [13]

There are a number of studies that analyse the possibility of using the content of trace elements in various biosubstrates as biomarkers of MS, as well as their use as food additives for metabolic correction [14, 15]. The results of numerous studies indicate that obesity-related metabolic disorders can be mediated by changes in the levels of trace elements in the body [16]. This is due to the fact that trace elements play an important role in the normal functioning of carbohydrate and lipid metabolism [15, 18]. The functioning of the body with an unbalanced diet can cause the development of various pathological conditions, including obesity and MS [14]. It is especially important to take this into account in adolescence, since this age period is characterized by a physiological restructuring of the body and is accompanied by a significant strain of functional systems [19]. In this regard, the purpose of this study was to study the elemental hair status of adolescent girls with different BMI levels and assess their average daily diet.

\section{Methods and Equipment}

The study involved healthy girls from 15 to 18 years old, college students in Orenburg. Groups of 800 students were selected for the study ( $n=100)$. After performing anthropometric studies (weight, height), three groups were formed depending on BMl: group I $(n=40)$ - BMI value from 18.5 to 24.9 (normal body weight), group II $(n=40)-B M I$ value from 25 to 29 (overweight - pre - obesity) and group III ( $n=20)$ - BMI value from 30 to 35 (obesity). The interpretation of BMI indicators used was in line with WHO recommendations [20] 
The actual nutrition assessment program was used to study nutrition. The elemental status was assessed by studying the chemical composition of hair using ICP-AES and ICP-MS methods in the laboratory of the ANCO «Center for Biotic Medicine».

The statistical processing of digital material was carried out using the application «Excel» and «Statistica 6.0». The statistical significance of differences between the groups was assessed using the Mann-Whitney U-test.

\section{Results}

Table 1 shows the indicators of physical development of students with normal body weight (group I), overweight (group II) and obesity (group III).

TABLE 1: The indexes of physical development, $\operatorname{Me}\left(Q_{25}-Q_{75}\right)$

\begin{tabular}{|c|c|c|c|}
\hline Indicator & Group I (BMI 18.5-24.9) & Group II (BMI 25-29) & Group III (BMI 30-35) \\
\hline Body mass & $56(52.2-60)$ & $74(67.2-75.5)^{b}$ & $84.5(83.2-85.7)^{b}$ \\
\hline Body height & $1.7(1.6-1.72)$ & $1.6(1.58-1.7)$ & $1.6(1.59-1.65)$ \\
\hline BMI & $20.3(19.5-21.6)$ & $26.6(25.3-28.9)^{b}$ & $33(32.5-33.5)^{b}$ \\
\hline
\end{tabular}

The values of student growth in all groups were almost the same. The studied anthropometric indicators of weight and BMI in groups II and III significantly changed when compared with group I, reflecting the dependence of BMI on weight.

The analysis of diets allowed us to conclude that the diet is unbalanced in terms of macro - and microelements consumption in all the study groups (table 2).

Consumption of $\mathrm{Na}, \mathrm{P}, \mathrm{Ca}, \mathrm{Mg}$ and $\mathrm{Zn}$ corresponded to the norms of physiological needs in all the study groups. Groups I and II showed the most pronounced excess consumption of $\mathrm{K}$ (by 12 and $13 \%$ ), Fe (by 37 and $42 \%$ ), $\mathrm{Cr}$ (by 28 and 6 \%) and $\mathrm{Cu}$ (by 18 and $6 \%$ ). In all three groups, there was a trend towards increased Mg consumption (Q75 above the recommended values by 52, $112 \%$ and $66 \%$ ). The supply of other chemical elements in the diet was insufficient. In all groups of students surveyed, there was a tendency to insufficient consumption of Se (by 99 \%) and I (by 31\%). In group III, there was a deficit in $\mathrm{Cu}(2 \%)$ and $\mathrm{Mn}(50 \%)$ consumption. It should be noted that with a general imbalance, students with obesity had lower values of the level of consumption of all studied macro-and microelements, except $\mathrm{Mg}$ and Se.

The results of the study of macro- and microelements in the hair of students are presented in table 3 . 
TABLE 2: The content of elements in the diet, mg/day, $M e\left(Q_{25}-Q_{75}\right)$

\begin{tabular}{l|c|c|c|c}
\hline Element & $\begin{array}{c}\text { Group I (BMI } \\
18.5-24.9)\end{array}$ & Group II (BMI 25-29) & Group III (BMI 30-35) & Normal range \\
\hline $\mathrm{Na}$ & $932.6(700.5-1500)$ & $1122(857-1726)$ & $719(474-964)$ & $200-1300$ \\
\hline $\mathrm{K}$ & $2822(2278-3667)$ & $2848(2112-3842)$ & $1574(1323-1824)^{a}$ & $400-2500$ \\
\hline $\mathrm{Ca}$ & $497.3(362.2-662.2)$ & $594.5(406.5-803.5)$ & $421.5(278.7-564.3)$ & $400-1200$ \\
\hline $\mathrm{Mg}$ & $363.9(242.8-608)$ & $402.4(317.1-851.2)$ & $519(371.2-666.8)$ & $55-400$ \\
\hline $\mathrm{P}$ & $974.1(796.8-1215)$ & $1088(737.3-1261)$ & $538.4(381.3-695.7)$ & $300-1200$ \\
\hline $\mathrm{Fe}$ & $24.7(20.1-32.2)$ & $25.6(20.6-33.5)$ & $15.3(14.7-15.9)^{a}$ & $4-18$ \\
\hline $\mathrm{Cr}$ & $0.045(0.029-0.063)$ & $0.037(0.032-0.050)$ & $0.020(0.016-0.024)$ & $0.011-0.035$ \\
\hline $\mathrm{Cu}$ & $1.18(0.941-1.54)$ & $1.06(0.762-1.37)$ & $0.49(0.40-0.58)^{a}$ & $0.5-1$ \\
\hline $\mathrm{Se}$ & 0.0039 & $0.004(0.0026-0,01)$ & 0.0052 & $0.01-0.05$ \\
\hline $\mathrm{Zn}$ & $(0.0026-0.0061)$ & & $(0.0034-0.0071)$ & \\
\hline $\mathrm{Mn}$ & $6.81(5.07-8.66)$ & $6.64(4.28-7.57)$ & $3.16(2.49-3.82)$ & $3-12$ \\
\hline $\mathrm{I}$ & $2.45(1.80-3.72)$ & $2.29(1.73-3.59)$ & $1.11(0.77-1.46)$ & $2-5$ \\
\hline
\end{tabular}

${ }^{1}$ «Norms of physiological needs in energy and food substances for various groups of the population of the Russian Federation» (Mr 2.3.1.24.32-08);

${ }^{a}$ Reliability of differences in performance with group I $-\mathrm{p}<0.05$;

${ }^{b}$ Reliability of differences in performance with group I $-\mathrm{p}<0.01$.

TABLE 3: Content of elements in hair, $\mathrm{mg} / \mathrm{kg}$, Me $\left(\mathrm{Q}_{25}-\mathrm{Q}_{75}\right)$

\begin{tabular}{|c|c|c|c|c|}
\hline Element & $\begin{array}{c}\text { Group I (BMI } \\
18.5-24.9)\end{array}$ & Group II (BMI 25-29) & Group III (BMI 30-35) & $\begin{array}{l}\text { National } \\
\text { average }^{1}\end{array}$ \\
\hline $\mathrm{Na}$ & 79.1 (49.1-143.7) & 85.6 (41.2-119.1) & $54(44.6-63.4)$ & $18-1720$ \\
\hline K & $25.5(15.4-46.7)$ & $27.6(20.3-42.4)$ & 19.6 (16.1-23.1) & $150-663$ \\
\hline Ca & 1834 (1 198-3 008) & 2477 (1 594-3 647) & 1433 (1 252-1 614) & $200-2000$ \\
\hline $\mathrm{Mg}$ & 205 (138.2-371.2) & 252.4 (141.3-320.7) & 148.3 (138.1-158.5) & $19,0-163$ \\
\hline$P$ & 128 (119.3-143.1) & $120.4(111.1-126.7)^{a}$ & 137.9 (137.2-138.5) & $75-200$ \\
\hline $\mathrm{Fe}$ & $16.5(12.6-22.7)$ & $15.8(11.3-21.2)$ & $12(11.1-12.9)$ & $5.0-25$ \\
\hline $\mathrm{Cr}$ & $0.26(0.20-0.36)$ & $0.27(0.22-0.31)$ & $0.19(0.18-0.20)$ & $0.1-20.0$ \\
\hline $\mathrm{Cu}$ & 12 (9.7-15.9) & $11.2(9.3-13.4)$ & 12.05 (10.4-13.6) & $7.5-80$ \\
\hline Se & $0.33(0.23-0.42)$ & $0.31(0.20-0.41)$ & $0.40(0.34-0.47)$ & $0.5-1.5$ \\
\hline $\mathrm{Zn}$ & 177.7 (161.6-198.4) & $161.1(148.3-172.1)^{a}$ & 188.9 (180.3-197.4) & $100-250$ \\
\hline $\mathrm{Mn}$ & $0.77(0.51-1.85)$ & $1.28(0.80-1.70)$ & $0.44(0.40-0.47)$ & $0.1-2.0$ \\
\hline I & 0.38 (0.17-0.99) & 0.34 (0.12-0.59) & $0.08(0.07-0.1)$ & $0.27-4.2$ \\
\hline
\end{tabular}

The content of $\mathrm{Na}, \mathrm{P}, \mathrm{Fe}, \mathrm{Cr}, \mathrm{Cu}, \mathrm{Zn}, \mathrm{Mn}$ and I in all groups of students was within the recommended values. In groups I and II, there was an increase in Mg level (by 25 and $54 \%$ ) and an increase in CA level in group II (by $23 \%$ ). In all three groups, there was a 
downward trend in the levels of $\mathrm{K}(83,82$ and $87 \%)$ and Se (34, 38, and $19 \%)$. Group III students had lower values of all studied macro- and microelements in hair, except Se, $P$ and Zn.

\section{Discussion}

Microelements are important for the prevention of a number of diseases and for improving overall health due to their diverse biological role in the body. Even a small number of them interact with macromolecules, including prohormones and biological membranes. Since most trace elements are not formed endogenously or are formed in insufficient quantities, they must be supplied to the body with a balanced and varied diet [21]. It is important to note that with a general imbalance of trace elements in the diet of all three groups studied, it was students with obesity who had the lowest values of the level of consumption of all the studied macro-and microelements. A group of scientists from the United States explain these results by the fact that, despite the increased caloric content of food, the diet of obese people often does not meet the recommended dietary requirements for the consumption of micronutrients [22].

Recent studies have shown that an imbalance of certain trace elements in the body may be associated with the frequency of obesity and increased fat deposition [2324]. For example, a low concentration of $\mathrm{Zn}$ in the blood has been shown to be associated with dyslipidemia, an inflammatory condition, and insulin resistance in overweight patients [25]. Data from the national health and nutrition survey in China provide epidemiological evidence that blood trace elements are associated with childhood and adolescent obesity [13]. However, hair is often used as a biosubstrate to study the content of elements. This method is characterized by ease of collection of the study sample and non-invasiveness. It is assumed that the content of elements in hair can provide useful prediagnostic information about the risk of developing obesity and MS [26]. It was found that people suffering from obesity are characterized by a lower content of a number of micro-and macronutrients in the hair relative to people with normal body weight [16]. This fact is also observed in our study, students with obesity recorded lower values of the content of all studied macro-and microelements in hair, except Se, $\mathrm{P}$ and $\mathrm{Zn}$. The detected elevated concentrations of $\mathrm{Ca}$ and $\mathrm{Mg}$ in the hair of normal and overweight students may indicate their pre-deficit state in the body [27]. The total lack of Se in the hair of all students, regardless of the BMI value, reflects the geochemical features of the territory of the Orenburg region $[28,29]$ 


\section{Conclusion}

$\mathrm{BMI}$ is correlated with the content of most of the studied elements. The levels of the following macro-and microelements had the greatest relationship with obesity: Ca, I, $\mathrm{Mg}, \mathrm{Mn}$. The identified imbalance in the diets of students indicates the need to adjust diets, as well as the need to improve the literacy of students in matters of balanced and complete nutrition, such as the prevention of obesity and MS.

\section{Conflict of Interest}

The authors have no conflict of interest to declare.

\section{References}

[1] Saklayen, M. G. (2018). The Global Epidemic of the Metabolic Syndrome. Current Hypertension Reports, vol. 20, issue 2, p. 12.

[2] Samson, S. L. and Garber, A. J. (2014). Metabolic Syndrome. Endocrinology \& Metabolism Clinics of North America, vol. 43, issue 1, pp. 1-23.

[3] Galassi, A., Reynolds, K. and He, J. (2006). Metabolic Syndrome and Risk of Cardiovascular Disease: A Meta-Analysis. The American Journal of Medicine, vol. 119 , issue 10, pp. 812-9.

[4] Li, W., et al. (2008). Association Between Metabolic Syndrome and Risk of Stroke: A Meta-Analysis of Cohort Studies. Cerebrovascular Diseases, vol. 25, issue 6, pp. 539-47.

[5] O'Neill, S. and O'Driscoll, L. (2015). Metabolic Syndrome: A Closer Look at the Growing Epidemic and Its Associated Pathologies. Obesity Research, vol. 16, issue 1, pp. 1-12.

[6] Engin, A. (2017). The Definition and Prevalence of Obesity and Metabolic Syndrome. Advances in Experimental Medicine and Biology, vol. 960, pp. 1-17.

[7] Despres, J. P. and Lemieux, I. (2006). Abdominal Obesity and Metabolic Syndrome. Nature, vol. 444, issue 7121, pp. 881-7.

[8] Collaborators, O., et al. (2017). Health Effects of Overweight and Obesity in 195 Countries Over 25 Years. The New England Journal of Medicine, vol. 377, issue 1, pp. 13-27.

[9] Ahirwar, R. and Mondal, P. R. (2019). Prevalence of Obesity in India: A Systematic Review. Diabetology \& Metabolic Syndrome, vol. 13, issue 1, pp. 318-21. 
[10] Vecchie, A., et al. (2018). Obesity Phenotypes and Their Paradoxical Association with Cardiovascular Diseases. European Journal of Internal Medicine, vol. 48, pp. 6-17.

[11] Bosello, O., Donataccio, M. P. and Cuzzolaro, M. (2016). Obesity or Obesities? Controversies on the Association Between Body Mass Index and Premature Mortality. Eating and Weight Disorders, vol. 21, issue 2, pp. 165-74.

[12] Kobo, O., et al. (2019). Normal Body Mass Index (BMI) Can Rule Out Metabolic Syndrome: An Israeli Cohort Study. Medicine (Baltimore), vol. 98, issue 9, pp. e14712.

[13] Jeong, H. S. (2018). The Relationship Between Workplace Environment and Metabolic Syndrome. Journal of Occupational and Environmental Medicine., vol. 9, issue 4, pp. 176-83.

[14] Robberecht, H., De Bruyne, T. and Hermans, N. (2017). Biomarkers of the Metabolic Syndrome: Influence of Minerals, Oligo- And Trace Elements. Journal of Trace Elements in Medicine and Biology., vol. 43, pp. 23-8.

[15] Shi, Y., et al. (2020). Trace Elements, PPARs, and Metabolic Syndrome. International Journal of Molecular Sciences, vol. 21, issue 7, pp. 2612.

[16] Skalnaya, M. G., et al. (2018). Hair Trace Elements in Overweight and Obese Adults in Association with Metabolic Parameters. Biological Trace Element Research, vol. 186 , issue 1, pp. 12-20.

[17] Kizalaite, A., et al. (2019). Determination of Trace Elements in Adipose Tissue of Obese People by Microwave-Assisted Digestion and Inductively Coupled Plasma Optical Emission Spectrometry. Biological Trace Element Research, vol. 189, issue 1, pp. 10-17.

[18] Panchal, S. K., Wanyonyi, S. and Brown, L. (2017). Selenium, Vanadium, and Chromium as Micronutrients to Improve Metabolic Syndrome. Current Hypertension Reports, vol. 19, issue 3, pp. 10.

[19] DeBoer, M. D. (2019). Assessing and Managing the Metabolic Syndrome in Children and Adolescents. Nutrients, vol. 11, issue 8, pp. 1788.

[20] Weir, C. B. and Jan, A. (2020). BMI Classification Percentile and Cut Off Points. In: StatPearls. Treasure Island (FL): StatPearls Publishing.

[21] Bogden, J. D. and Klevay, L. M. (2000). Clinical Nutrition of the Essential Trace Elements and Minerals. USA: Humana Press; Nutrition and Health.

[22] Frame-Peterson, L. A., et al. (2017). Nutrient Deficiencies are Common Prior to Bariatric Surgery. Nutrition in Clinical Practice, vol. 32, issue 4, pp. 463-9.

[23] García, O. P., Long, K. Z. and Rosado, J. L. (2009). Impact of Micronutrient Deficiencies on Obesity. Nutrition Reviews, vol. 67, issue 10, pp. 559-72. 
[24] Skrypnik, M. D., et al. (2019). Influence of Endurance and Endurance-Strength Training on Mineral Status in Women with Abdominal Obesity: A Randomized Trial. Medicine (Baltimore), vol. 98, issue 12, pp. e14909.

[25] García, O. P., et al. (2013). Zinc, Iron and Vitamins A, C and e are Associated with Obesity, Inflammation, Lipid Profile and Insulin Resistance in Mexican School-Aged Children. Nutrients., vol. 5, issue 12, pp. 5012-30.

[26] Choi, H. J., et al. (2019). The Association between Mineral and Trace Element Concentrations in Hair and the 10-Year Risk of Atherosclerotic Cardiovascular Disease in Healthy Community-Dwelling Elderly Individuals. Nutrients, vol. 11, issue 3, pp. 637.

[27] Skalny, A. V. (2004). Khimicheskie elementy v fiziologii i ekologii cheloveka. Moscow: ONIKS 21 Vek Publ, p. 216.

[28] Notova, S. V., et al. (2006). Necessity of Taking into Account Regional Peculiarities When Modelling the Processes of Element Interactions in a Human Body. Vestnik Orenburg State University, vol. 2, pp. 59-63.

[29] Skalnyy, A. V., et al. (2014). Regional Features of the Elemental Homeostasis as an Indicator of Ecological and Physiological Adaptation. Ekologia cheloveka vol. 9, pp. 14-17. 